\title{
Anesthetic Considerations in a Patient With Plexiform Neurofibromatosis: A Case Report
}

\author{
Pardis Soltanpoor ${ }^{1 *}$, Faranak Behnaz ${ }^{1}$, Mehdi Farokhi², Reza Jalili Khoshnood², Hamid Reza \\ Azizi Farsani ${ }^{1}$
}

${ }^{1}$ Department of Anesthesiology, Shahid Beheshti University of Medical Sciences, Tehran, Iran ${ }^{2}$ Department of Neurosurgery, Shahid Beheshti University of Medical Sciences, Tehran, Iran

\begin{abstract}
Plexiform neurofibromatosis is an uncommon variant of neurofibromatosis type 1 (NF1) (Von Recklinghausen's disease). There is a greater prevalence of neurofibromatosis 1 in patients with other neoplasms, such as rhabdomyosarcomas, gastrointestinal stromal tumors (GISTs), pheochromocytomas, carcinoid tumors and ganglioneuromas. We report the anesthetic implications of a case of a 33 year old patient with plexiform neurofibromatosis and a history of pheochromocytoma which was operated on previously. He presented with painless swelling on upper eye-lead since childhood and had multiple caféau-lait spots and neurofibromas on the trunk. The surgery was done in two sessions first on the plexiform neurofibroma of the eye followed by the operation on the brain mass.

Keywords: Plexiform neurofibromatosis; Anesthetic implications; Pheochromocytoma.
\end{abstract}

\author{
*Correspondence to \\ Pardis Soltanpoor \\ Department of Anesthesiology, \\ Shahid Beheshti University of \\ Medical Sciences, Tehran, Iran \\ Tel: +98 9144069389' \\ Email: pardis.soltanpoor@ \\ gmail.com
}

Published online 20 December 2018

Citation: Soltanpoor P, Behnaz F, Farokhi M, Jalili Khoshnood R, Azizi Farsani HR. Anesthetic considerations in a patient with plexiform neurofibromatosis: a Case report. Int Clin Neurosci J. 2018;5(4):169-170. doi:10.15171/icnj.2018.30.

\section{Introduction}

Neurofibromatosis is an autosomal dominant disorder characterized by neuroectodermal tumors. ${ }^{1}$ Neurofibromatosis type 1 (NF1), or Von Recklinghausen 's disease is a rare genetic disorder which presents with multiple benign tumors of nerve and skin (neurofibromas) and areas of abnormal coloration of the skin (café-au-lait spots). ${ }^{2}$ NF1 gene has been localized on chromosome 17 and represents $95 \%$ of neurofibromatosis cases with the incidence rate of 1 in 3500 newborns and prevalence of 1 in $4500 .^{3}$

Plexiform neurofibromas represent an uncommon variant $(30 \%)$ of NF1 in which neurofibromas arise from multiple nerves as deforming masses involving connective tissue and skin, therefore, clinical description of the bag of warms used. ${ }^{4}$

\section{Case Report}

A 33 years old male patient presented in our neurosurgical department with the complaint of painless swelling in upper eye-lead since childhood. He had a history of pheochromocytoma which was operated on three months earlier. There was no evidence of pheochromocytoma at the time of the operation and metanephrine, normetanephrine and VMA levels in blood and urine were within the normal range. The diagnosis of NF-1 made according to the presence of two or more criteria of the disease.

\section{Physical Exam}

Dermatologic Status

Multiple café-au-lait spots with diameter $>1.5 \mathrm{~cm}$ on the chest and back, several neurofibromas on the trunk, axillary and inguinal freckling. The mucous membranes were not affected.

\section{Ophthalmologic Status}

Visual acuity was $6 / 6$ in both eyes. A neurofibroma plexiform was present on the upper eye-lead of the right eye.

\section{Head and Neck Examination}

He had adequate mouth opening, normal neck and temporomandibular joint movements and a mallampati class 1 on oropharyngeal examination.

\section{Lab and Imaging Studies, Histologic Findings and Consultations \\ The standard lab test values were within the normal range. CT scan showed soft tissue lesion with widening of orbital canal and mass effect on optic nerve and apex of the orbit. The histological results confirmed the diagnosis of neurofibromatosis (Figure 1).}

\section{Anesthetic Implications}

General anesthesia was planned for the surgery. After premedication with $20 \mathrm{mg}$ midazolam, $200 \mu \mathrm{g}$ fentanyl, and $100 \mathrm{mg}$ lidocaine, the induction of anesthesia was done using $100 \mathrm{mg}$ propofol and $50 \mathrm{mg}$ atracurium. The patient experienced transient paroxismal atrial contractions after intubation which resolved after the administration of the maintenance dose. The maintenance of anesthesia provided with an infusion of $10 \mathrm{mg} / \mathrm{kg} / \mathrm{h}$ propofol and infusion of $0.05 \mu \mathrm{g} / \mathrm{kg} / \mathrm{min}$ remifentanil. The patient's 


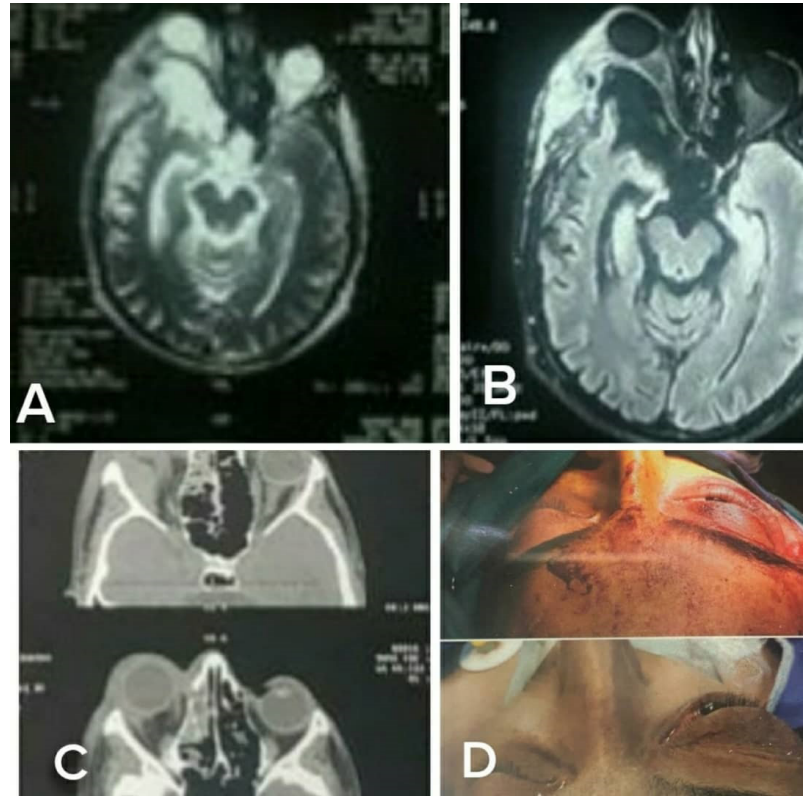

Figure 1. A \& B . Magnetic resonance imaging shows hypointense lesions in $\mathrm{T} 1$ and hyperintense lesions in $\mathrm{T} 2$ posterior to the right orbital cavity. C . In computed tomography a soft tissue lesion with widening of orbital canal and mass effect on optic nerve and apex of the orbit causing proptosis. D . Pre-op and post-op images of the patient with obvious proptosis in right upper eye-lead.

hemodynamic status was normal during the procedure, and the heart rhythm was normal sinus rhythm. Due to the massive amount of bleeding during the evacuation of neurofibroma plexiform, the surgery team decided to postpone the resection of brain mass. The patient received 3 units of isogroup crossmatched packed cells, and the urine output was $400 \mathrm{cc}$ during 5 hours of surgery. General anesthesia administered was uneventful during the second procedure.

\section{Discussion}

Neurofibromatosis is an autosomal dominant disease affecting all organs. The diagnosis was made according to the presence of two or more of the following criteria:
A) 6 or more café-au-lait macules $(>0.5 \mathrm{~cm}$ in children and $>1.5 \mathrm{~cm}$ in adults)
B) 2 or more cutaneous or subcutaneous neurofibromas or one plexiform neurofibroma
C) Axillary or inguinal freckling
D) Optic glioma
E) 2 or more lisch nodules (iris hamartomas visualized on slit lamp examination)
F) Sphenoid wing dysplasia or bowing of long bone (with or without pseudoarthrosis)
G) First degree relative with an NF1 diagnosis ${ }^{2}$

Neurofibromas are the characteristic lesions which can occur anywhere including oropharynx and larynx resulting in difficulty in laryngoscopy. ${ }^{5}$ Painless dislocation of cervical vertebrae has been reported in a patient with multiple cervical neurofibromas therefore preop radiological exam has been suggested to avoid spinal cord damage during laryngoscopy. ${ }^{6}$ Pulmonary pathologies include pulmonary fibrosis and cystic lung disease. Its cardiovascular manifestations include hypertension which might associate with pheochromocytoma or renal artery stenosis which may be bilateral. ${ }^{5}$ Pheochromocytoma affects between $0.1 \%-5.7 \%$ of patients with NF1 but almost $25 \%$ of patients with pheochromocytoma have the disease. The anesthesiologist should also pay attention to the possibility of severe hemorrhage during the surgery on plexiform neurofibromas. ${ }^{7}$ The arterial lesions with different morphologies including fusiform intimal narrowing or nodular or aneurismal formations can be present. CNS tumors account for the major portion of morbidity and mortalities in these patients. Involvement of brainstem structures can cause central hypoventilation syndrome leading to prolonged postop weaning. ${ }^{5}$ The anesthesiologist should take into account the increased risk of epilepsy, learning difficulties and the possibility of undiagnosed CNS tumors during the assessment for patients undergoing surgery due to cranial and spinal masses. $^{7}$

\section{Patient Outcome}

The patient discharged without any neurological deficit.

\section{Conflict of Interest Disclosures}

The authors declare that they have no conflict of interests.

\section{Ethical Statement}

An informed consent form for publication of the study was obtained for the patent.

\section{References}

1. Dimitrova V, Yordanova I, Pavlova V, Valtchev V, Gospodinov D, Parashkevova B, Balabanov C, et al. Case of neurofibromatosis type 1. Journal of IMAB. 2008;14:63-67. Doi:10.5272/ jimab.14-1-2010.63.

2. Sayah C, Benmahmoud M, AitYahiaS, Soualili Z. Neurofibromatosis type 1 (NF1): case report and review of literature. J Child Dev Disord. 2016;2:3. doi: 10.4172/2472-1786.100028

3. Drouet A1, Wolkenstein P, Lefaucheur JP, Pinson S, Combemale P, Gherardi RK, et al. Neurofibromatosis 1-associated neuropathies: a reappraisal. Brain. 2004;127(9):1993-2009. doi: 10.1093/brain/ awh234.

4. Tchernev G, Chokoeva AA, Patterson JW, Bakardzhiev I, Wollina U, Tana C. Plexiform neurofibroma: a case report. Medicine (Baltimore). 2016;95(6):e2663.

5. Bagam KR, Vijaya DS, Mohan K, Swapna T, Maneendra S, Murthy SG. Anaesthetic considerations in a patient with von recklinghausen neurofibromatosis. J Anaesthesiol Clin Pharmacol. 2010;26(4):553-4.

6. Lovell AT, Alexander R, Grundy EM. Silent, unstable, cervical spine injury in multiple neurofibromatosis. Anaesthesia. 1994;49(5):453-4.

7. Hirsch NP, Murphy A, Radcliffe JJ. Neurofibromatosis: clinical presentations and anaesthetic implications. $\mathrm{Br} J$ Anaesth. 2001;86(4):555-64 